\title{
Research on the Impact of Five Science and Technology Plans of Guangdong Province on Industrial Innovation Chain
}

\author{
Yuhui Yu \\ School of Business Administration, South China University of Technology, Guangzhou, China \\ Email: 1286036375@qq.com
}

How to cite this paper: Yu, Y.H. (2019) Research on the Impact of Five Science and Technology Plans of Guangdong Province on Industrial Innovation Chain. Open Journal of Business and Management, 7 , 124-134.

https://doi.org/10.4236/ojbm.2019.71009

Received: December 10, 2018

Accepted: December 30, 2018

Published: January 2, 2019

Copyright $\odot 2019$ by author and Scientific Research Publishing Inc. This work is licensed under the Creative Commons Attribution International License (CC BY 4.0). http://creativecommons.org/licenses/by/4.0/

\begin{abstract}
The science and technology planning system is the basic form of government organization of scientific research and technology development activities. It is an action plan that affects the future development of science and technology and the related environment. It is also the government's rational allocation of scientific and technological resources, regulation of market and scientific research, and promotion of scientific and technological progress. An effective means of economic and social development is one of the important tools in science and technology policy. This paper studies the science and technology policy of Guangdong Province, namely the "five major science and technology plans" from the perspective of industrial innovation chain. Firstly, it introduces the theory of industrial innovation chain; then studies the public goods, externalities and uncertainties in the industrial innovation chain of market failures; finally analyzing the role of the "Five Science and Technology Programs" in market failures in the industrial innovation chain.
\end{abstract}

\section{Keywords}

Industrial Innovation Chain, Market Failure, Science and Technology Plans

\section{Introduction}

The 19th National Congress of the Communist Party of China proposed that innovation is the first driving force for development. We must continue to strengthen basic research, strengthen the application of basic research, and continue to implement major science and technology projects. In May 2016, the "National Innovation Driven Development Strategy Outline" issued by the CPC Central Committee and the State Council also proposed that technology and 
economy should be integrated, give full play to the vitality of each innovation subject, and make the innovation chain organically connect, making innovation governance more scientific and improving innovation efficiency. The Guangdong Provincial Party Committee and the Provincial Government fully implemented the Party Central Committee's strategy on innovation-driven development, taking innovation-driven development as the core strategy, priority strategy and overall grasp. Through comprehensively deepening the reform of the science and technology system, the implementation of the innovation-driven development strategy, Guangdong Province's science and technology innovation Drive into the development of the "fast lane", the rapid growth of science and technology research and development investment. In 2015, the province's R\&D expenditure was 179.82 billion yuan, an increase of $12.0 \%$ over the previous year. The proportion of science and technology research and development funds to GDP reached 2.5\%, a record high. Guangdong's fiscal science and technology expenditure was 89.816 billion yuan, accounting for $15.26 \%$ of the provincial general public budget expenditure, which is much higher than the proportion of the state's fiscal science and technology expenditures to the general public budget (3.5\%).

As an important way to realize the science and technology plan, the science and technology plan project is important for exerting the macro-control and social guidance role of science and technology plan, solving major scientific and technological problems in economic and social development, enhancing industrial competitiveness, and promoting China's economy, science and technology and social development significance. In 2014, the "Guangdong Province Major Science and Technology Special Implementation Plan (2014-2018)" issued by Guangdong Province clearly organized 9 major science and technology projects by 2018 , including computing and communication integrated chips, mobile internet key technologies and devices, cloud computing and Big data management technology, new printed display technology and materials, visible light communication technology and standard optical components, intelligent robots, new energy vehicle batteries and power systems, stem cell and tissue engineering, additive manufacturing (3D printing) technology, and planned to 2018 Each year, 50 - 100 major science and technology projects are organized. As of 2016, Guangdong Province's major science and technology projects have organized 3 batches and funded more than 100 major science and technology projects. In 2016, the "Implementation Plan for the Management Reform of Guangdong Provincial Financial Science and Technology Plan (Special, Fund, etc.)" (Guangdong [2016] No. 14) was integrated into the science and technology funds scattered in various departments, and the "Technology Development Special Project" was established. "Funding" to build a "511" science and technology planning system, namely "Basic and Applied Basic Research (Natural Science Fund)", "Public Welfare Research and Capacity Building", "Frontiers and Key Technology Innovations", "Industrial Technology Innovation and Technology Finance Combination" and "collaborative innovation and platform environment construction" as 
the "five major science and technology plans".

Give full play to provincial science and technology plans to improve regional scientific and technological strength, enhance comprehensive competitiveness, promote industrial transformation and upgrading, and strengthen the close integration of technology and economy. Deploying an innovation chain around the industry chain, improving the capital chain around the innovation chain, coordinating basic research, applied research, experimental development, transformation of results, industrial development, etc., and actively and effectively serving economic restructuring and upgrading and upgrading, building an innovative economy with core competitiveness.

With the rapid development of the social economy and high-tech, science and technology plans are becoming more and more important for promoting the significance of national science and technology, economy and social development. Studying the relationship between the science and technology planning system and the industrial innovation chain, fully understanding the role of the science and technology planning system in the industrial innovation chain, can be used to supplement the shortcomings in the innovation process and strengthen the research related to the weak links of industrial innovation, and solve the industry. The problem of market failure in the innovation chain further expands the theory of industrial innovation chain.

\section{Industry Innovation Chain Theory}

The industrial innovation chain aims to enhance the industrial innovation capability and optimize the innovation system [1]. It promotes the coupling of the industrial chain and innovation chain around major industrial applications and key technological breakthroughs, and promotes enterprise-oriented, government, scientific research institutions, universities and intermediaries. And so on, so as to form a network chain innovation system that integrates innovative ideas, research and development activities, transformation of results, industrialization and marketing [2].

Roth Well [3] believes that the idea of the industrial innovation chain stems from technology promotion and market pull, and the coupling of the industry chain and the innovation chain through the feedback loop. Therefore, the industrial innovation chain can be intuitively understood as the organic coupling between the industrial chain and the innovation chain, and is an effective countermeasure to solve the disconnection between the industrial chain and the innovation chain. Its effective operation is actually to build a collaborative innovation mechanism.

Yu Binbin [4] (2011) discusses the relationship between the industrial chain and the innovation chain from the perspective of industrial clusters. The upstream enterprises provide products and services for downstream enterprises, while providing a source for downstream enterprise innovation, industry chain and innovation chain related substances, energy, Information is docked through the cluster platform. Enterprises in the cluster share benefits, exchange and 
cooperation, and compete with each other to create power for enterprise innovation. The formation of cluster innovation comes from the achievement of the interests of upstream and downstream enterprises. Cluster innovation is the integration of industry chain and innovation chain. Create possibilities.

Zhu Ruibo [5] (2012) takes Shanghai's high-tech industry as the research object, and believes that the reason why Shanghai's high-tech enterprises are "high-tech is not high" is that the "double chain" of the industrial chain and the innovation chain are separated from each other, and they are not integrated and realize double-chain. The integration should be innovative investment and financing mechanism, let the government's innovation funds and social funds transfer to the innovation chain, build an open innovation network mechanism of production, education and research, and form a front-end basic research, mid-end technical services and successful transformation of the back-end and industrialization of the project. The complete chain enables the integration of the industrial chain and the innovation chain.

Xing Chao [6] (2012) takes the big science project as an example, analyzes the effective organization way of the integration of industry chain and innovation chain, and believes that the systematic nature of organization management provides the possibility of the integration of double chain, the certainty of industry and the promotion of system integration innovation.

He Xiaoyu [7] (2013) explained the bottlenecks in the integration of industrial chain and innovation chain from the perspective of China's low-carbon industry development, deepening the cooperation between schools and enterprises, increasing investment in innovation, giving full play to market regulation, and increasing government macro-control to achieve low carbon The conditions for rapid integration of industrial double-chain.

Liu Runsheng [8] (2014) puts forward that the innovation chain should be arranged around the industrial chain in view of the current lack of integration of science and technology and economy in China and the low conversion rate of scientific and technological achievements. Brechi and Bamfield [9] (1997) define the industrial innovation chain system, that is, "a group of companies actively develop and manufacture industrial products, and create and use industrial technologies". Therefore, an industrial innovation system mainly includes participants in special industries and their interrelationships. Moreover, most of the functions of the industrial innovation chain system are realized by participants in the industry.

\section{Market Failures in the Industrial Innovation Chain}

The practice of human socio-economic development shows that the market mechanism is by far the most efficient and dynamic resource allocation means and economic operation mechanism, and it has the functional advantages unmatched by any other means and mechanisms [10]. However, due to the weaknesses and shortcomings of the market itself, such as spontaneity, blindness, and 
lag, if the government intervention is completely abandoned, it will inevitably lead to market failure. Enterprises are one of the main players in the industrial innovation chain. At the same time, the industrial innovation chain, as a combination of industrial innovation and economy, has obvious public product, externality and uncertainty, and there are obvious market failures, which directly lead to enterprises. The weakening of innovation enthusiasm leads to inefficiency in the allocation of innovative resources. The government-implemented science and technology plan can reasonably intervene in enterprise innovation, and can effectively overcome market failures in the industrial innovation chain, thus forming a scientific and effective industrial innovation operation mechanism [11].

\subsection{The Nature of Public Goods in the Industrial Innovation Chain}

Industrial innovation has obvious public product properties. The industrial innovation chain is a complex system, and its input-output process is difficult to express through a functional relationship. Therefore, simply defining industrial innovation as a public product or a private product is one-sided, and the output of the industrial innovation chain is Contains the nature of public, mixed and private products. The industrial innovation chain involves a series of economic and technological activities such as basic research, applied research, experimental development research, product production and commercial application. Different stages have different products, and different products have different properties. The products in the industrial innovation chain mainly include products of knowledge form, products of patent form and products of physical form. The stronger the product foundation, principle and knowledge in the industrial innovation chain, the more widely used, the stronger its non-competitive and non-exclusive nature, the more it has the public product nature; the closer it is to the commercialization stage The products are more privately-owned; in addition, there are many industrial innovation products in between, they are both public goods and private products, and they are mixed products.

\subsection{Externalities in the Industrial Innovation Chain}

The externalities of the industrial innovation chain are mainly reflected in the spillover effect. Investors engaged in research and development activities are the rewards brought by innovations for industrial innovation achievements. However, because the results of industrial innovations have the nature of public products to varying degrees, investors cannot fully enjoy the benefits brought by industrial innovations, which form the spillover effect of industrial innovation. According to different levels, it can be divided into the following four situations: First, the spillover effect in the industry, which is the market share of innovators who expand their products through innovative activities, so that other companies can be inspired and based on this. Imitation or new innovation is the improvement of product quality and performance; second, the spillover effect between industries, mainly manifested in the spillover form of inter-industry 
technology, production, management, income, etc.; the third is the spillover effect in the country, which can enhance a country The original product has comparative advantages and product leadership; the fourth is the international spillover effect, which has changed the bottleneck of the technology supply of the host country and enhanced the industrial innovation capability of the host country. The spillover positive effect of the industrial innovation chain can enable other companies to reduce innovation costs and improve the overall level of innovation, thereby increasing the diffusion rate of industrial innovation results and increasing the wealth of the entire society.

\subsection{Uncertainty in the Industry Innovation Chain}

The industrial innovation process also has obvious uncertainties. The industrial innovation chain is a tortuous and complex system. Because there is no direct reference and experience, there are many different links and jumps. Each link may produce many unexpected situations. At the same time, the industrial innovation process is also the process of multi-role participation has different value choices and interest preferences in its development path and development direction. Innovators cannot accurately control the progress, direction, impact, and results of R \& D efforts.

From the content point of view, the uncertainty of the industrial innovation chain mainly includes the following four aspects: technical uncertainty, market uncertainty, environmental uncertainty and income uncertainty. The technical uncertainty means that due to the inability to accurately predict the bottlenecks in technology and process before innovation, there is a possibility of failure in technology development and production process development, and the uncertainty of technical effects also leads to industrial innovation results. Whether the results of industrial innovation can be accepted by the market is reflected through the market. Therefore, market uncertainty is of decisive significance for the industrial innovation process. "Innovation activities are faced with a world of uncertainty. The existence of uncertainty is not only the basis for innovation, but also the obstacle to innovation."

The uncertainty of industrial innovation will inevitably lead to high risk of industrial innovation, which will seriously affect The enthusiasm of private enterprises to undertake industrial innovation activities independently, resulting in the market failure of the allocation of innovative resources, resulting in industrial innovation time lag, from the initial design ideas or invention patents to the final use as a practical commodity to enter the market and for consumers The process of acceptance is extended.

\section{Functions of the Five Major Science and Technology Projects in the Industrial Innovation Chain}

On the basis of scientific prediction, the science and technology plan combines current or future development needs, and the scientific and technological development action plan determined by expert argumentation is scientific and 
forward-looking, which makes it easy to become a common vision of technological development, and thus unify the scientific and technological resources. Use is instructive and appealing. This is an effective form of industrial chain innovation through government funding. It can effectively solve the phenomenon of public goods market failure in industrial innovation.

\subsection{Basic and Applied Basic Research Functions in the Industrial Innovation Chain}

The basic research is mainly to obtain new knowledge about the basic principles of phenomena and observable payments, and to carry out empirical work or theoretical work for the purpose of specific or specific applications. Under the background of the continuous transfer of science and technology competition to basic scientific research, basic scientific research has increasingly become the core driving force of industrial innovation. Strengthening basic and applied basic research has a significant and far-reaching impact on Guangdong's breakthrough in achieving forward-looking and original innovation.

The science and technology plans of basic and applied basic research in Guangdong Province can be divided into four major categories. One is the major basic research and cultivation project. The main research content is to carry out basic and applied basic research around strategic emerging industries in our province; the main research content of the project is to carry out basic and applied basic research around the important needs of the province's economic and social development. The third is the free application project, which is divided into a free exploration project and a Guangdong basic research strategy and management research project. The main research contents are free exploration and Guangdong basic research development strategy, institutional mechanism innovation, innovation platform system, project and intellectual property management.

Through this series of project design, we can effectively solve the problems of creative production and creative sources in the industrial innovation chain, give significant support in the identified industries, and purposefully improve the ability of industrial innovation. The fourth is the basic research projects that are not specific to specific industries, and the largest range of sources for expanding innovative ideas. The government has taken on some uncertain risks, enabling companies to better innovate in the industry.

\subsection{The Function of Public Welfare Research and Capacity Building in the Industrial Innovation Chain}

The Public Welfare Research and Capacity Building Project is a science and technology project used by Guangdong Province to support organizations that are oriented to industry and society. The key areas supported by this project include reform and innovation of provincial scientific research institutions, construction of basic science and technology conditions, sharing of large-scale instruments and equipment, large-scale scientific projects of national ministries 
and commissions in Guangdong Province, citation development for industrial and social livelihoods, and soft science research.

One of the main purposes of this kind of science and technology project is to support common technical research and technical product development in various fields of the industry, establish provincial key laboratories, and focus on the economic, social and technological development strategies of Guangdong Province to improve the independent innovation capability and promotion of enterprises. The industry's technological progress is the purpose of carrying out scientific research, focusing on applied technology research and technology development. Master independent intellectual property rights, research and propose international, national, industry and local standards, promote the integration of production, education and research, enhance technological innovation and transformation of results, guide the application of new technologies and the transformation of results, and bring into play the common technology integration, high-end technology public services and radiation With action. The main purpose is to solve the problem of research and development in the creative transformation of the industrial innovation chain, that is, based on the existing basic research, to further develop the technology of the target and promote the development of the entire industrial technology. This can further expand the spillover effect in the process of industrial innovation, so that the entire industry can benefit.

\subsection{Frontiers and Key Technology Innovations in the Industry Innovation Chain}

Frontiers and key technology innovation projects refer to projects that carry out cutting-edge technology research, implementation of major science and technology projects, research in related fields, and technological innovation in Guangdong Province. On the basis of full research, the government has guided the establishment of this technology project to guide the various entities in the industrial innovation chain to actively participate in the frontier and key technological innovation issues that the government urgently needs to solve.

One of the characteristics of this type of project is that the government will explain what needs to be studied, the research objectives, and the criteria for judging the research objectives. Then, the innovation entities independently declare themselves, and the government organizes experts to conduct comprehensive evaluations to determine the recipients of the science and technology plan projects. The key areas supported are: key core and common technology research that plays an important supporting role in the industrial development of our province, and the implementation of major science and technology projects; key industry and common technology solutions designed in the first, second and third industries and social and people's livelihoods. Research and development; Guangdong-Hong Kong joint funded projects and technology-based small and medium enterprises (SMEs) technology independent innovation projects. Frontier and key technology innovation projects in the industry 
innovation chain of specific technology research and development and demonstration have an important role in promoting innovation output and expanding the scope of innovation diffusion.

\subsection{The Combination of Industrial Technology Innovation and Technology Finance in the Industry Innovation Chain}

Industrial technology innovation and technology integration projects refer to projects used to guide and drive social capital to participate in technological innovation and support the transformation and industrialization of independent innovation achievements.

Such projects focus on the following contents: First, mobilize credit institutions in Guangdong Province to expand the scale of credit projects for science and technology projects and technology-based SMEs, and upgrade credit lines for science and technology projects and technology-based SMEs. Second, mobilize the province's venture capital institutions for SMEs. The third is the subsidy for R \& D expenses and technology insurance fees for technology-based enterprises; the fourth is the construction of the province's science and technology financial service system; the fifth is the industrial technology innovation and industrialization project; and the provincial government has formulated other projects that need to be supported. For example, the special project of science and technology ventures is set up to explore the mechanism of establishing financial science and technology plan funds and venture capital to support science and technology projects, and establish a sound linkage mechanism between financial funds and social capital investment in science and technology industries, which can accelerate the investment of angels in Guangdong Province. With the development of venture capital, investment institutions such as venture capital investment enterprises and venture capital management enterprises (hereinafter collectively referred to as venture capital institutions) are encouraged to invest more in science and technology small and medium-sized enterprises in the early stage and in the early and middle stages to promote the transformation and industrialization of scientific and technological achievements.

Industrial technology innovation and technology integration projects can promote innovation output in the industrial innovation chain, promote the transformation of innovation results into products for sale and use, and achieve industrialization, thereby reducing market uncertainty in industrial innovation.

\subsection{The Function of Collaborative Innovation and Platform Environment Construction in the Industrial Innovation Chain}

Collaborative Innovation and Platform Environment Construction Project refers to the project of collaborative innovation of industry, academia and research, international scientific and technological cooperation, innovation carrier and innovative service system construction and creation of innovative and entrepreneurial environment. The key support contents of this kind of project include the construction of a new R \& D institution with independent legal person quali- 
fication formed by the combination of industry, university and research, the establishment of a public innovation platform supporting the cooperation of the industry, academia and research, and the industrial technology innovation alliance, and support the implementation of the public innovation platform in Guangdong Province. Significant scientific and technological achievements will be transformed into provincial-level or international scientific and technological cooperation to produce major achievements in industrialization projects; support for the construction of science and technology service systems, innovative technology transfer mechanisms, improvement of technology trading systems, organization of scientific and technological achievements exhibitions, intellectual property transformation applications and outstanding scientific and technological achievements industries To support enterprises or science parks, university research institutions, etc. to carry out personnel training and introduction work. Collaborative innovation and platform environment construction projects have created favorable conditions for the transformation of innovation achievements and innovation diffusion in the industrial innovation chain, greatly promoting the diffusion of industrial innovation results in the market and realizing the benefits of innovation.

\section{Conclusions}

Generally speaking, industrial innovation products have different public product properties, and industrial innovation, especially in the early stage of research and development, requires high cost input. Therefore, enterprises or individuals may choose if their costs are not fully compensated. Accepting external technology spillovers rather than making independent innovations, when all companies or private individuals choose this optimal strategy, it will lead to the stagnation of innovation and the market failure of industrial innovation. Therefore, when the market mechanism cannot realize the effective allocation of innovation resources, in order to coordinate private interests (including corporate interests and personal interests) and social interests, the government can intervene in industrial innovation through means of scientific and technological planning to optimize the industrial innovation chain system. The externality of the spillover effect of industrial innovation is an important reason for the failure of the science and technology innovation market.

Therefore, it is necessary for the government to effectively control the economic effects of technological innovation by adjusting the development direction of science and technology plans, to ensure the source of innovation of industrial innovation-innovational gains, to stimulate the enthusiasm of enterprise industrial innovation, and to make the supply of scientific and technological innovation reach the optimal level of society. In order to stimulate enterprises to invest in risky industrial innovation activities and shorten the time lag of industrial innovation, it is necessary to construct an effective industrial innovation operation mechanism. Government-implemented science and technology 
projects can drive private and public resources to correct the under-investment that may occur in industrial development and application, to directly or indirectly disperse and share industrial innovation risks and promote industrial innovation activities.

\section{Conflicts of Interest}

The author declares no conflicts of interest regarding the publication of this paper.

\section{References}

[1] Zhang, H.Y. and Dai, W.L. (2011) Conceptual Model of Regional Innovation Value Chain Based on Innovation Value Chain. Science and Technology Progress and Countermeasures, No. 1, 28-32.

[2] He, Y.L. (2006) Analysis of the Positive External Effect Path of Magnifying Science and Technology Plan-Enlightenment of Finnish Science and Technology Plan Organization Mechanism to China. Science Research, No. S2, 490-493.

[3] Rothwell. P. (1992) Successful Industrial Innovation: Critical Factors for the 1990s. R\&D Management, 22, 221-239 https://doi.org/10.1111/j.1467-9310.1992.tb00812.x

[4] Yu, B.B. (2011) Research on Industrial Cluster Industry Chain and Innovation Chain Based on Evolutionary Game Model. Science and Science and Technology Management, No. 11, 111-117.

[5] Zhu, R.B. (2012) The Development of High-Tech Industry in Shanghai during the Twelfth Five-Year Plan Period: Research on the Integration Strategy of Innovation Chain and Industrial Chain. Shanghai Economic Research, No. 7, 94-106.

[6] Xing, C. (2012) The Effective Organization of the Combination of Innovation Chain and Industrial Chain-Taking Big Science Engineering as an Example. Science and Science and Technology Management, 33, 117-119.

[7] He, X.Y. (2013) Research on the Development Path of Low Carbon Industry in China-Based on the Perspective of the Integration of Industry Chain and Innovation Chain. Science Research, 22, 317-321.

[8] Liu, R.S. (2014) Establishing an Innovation Chain around the Industry Chain. Wei Shi (Modern Management), No. 2, 35.

[9] Bamfield, P. (2007) The Innovation Chain, Research and Development Management in the Chemical and Pharmaceutical Industry. WILEY-VCH Verlag GmbH \& co., Weinheim.

[10] Samuelson, P., Nordhaus, W., Shen, X., et al. (2008) Economics. 18th Edition, People's Posts and Telecommunications Press, Beijing, 27-31.

[11] Qiao, D.M. and Li, Z.F. (2006) The Role and Implementation of Science and Technology Planning in the Integration of Science and Technology Resources. Science and Science and Technology Management, No. 5, 14-19. 